James Russell Connelly

Department of Philosophy

Trent University, Durham-GTA
Original Scientific Paper

UDK 165.17 Витгенштајн Л.

14 Витгенштајн Л.

161/164 Витгенштајн Л.

\title{
ON WITTGENSTEIN'S TRANSCENDENTAL DEDUCTIONS
}

\begin{abstract}
In this paper, I aim to shed light on the use of transcendental deductions, within demonstrations of aspects of Wittgenstein's early semantics, metaphysics, and philosophy of mathematics. I focus on two crucial claims introduced by Wittgenstein within these transcendental deductions, each identified in conversation with Desmond Lee in 1930-31. Specifically, the claims are of the logical independence of elementary propositions, and that infinity is a number. I show how these two, crucial claims are both demonstrated and subsequently deployed by Wittgenstein within a series of transcendental deductions, a series which begins with extensionalism as a generalized condition of sense on propositions, and in the context of which are then derived various, further, significant and unobvious presuppositions generated by that generalized condition of sense. In addition to clearing up deductions of these two, aforementioned claims, I also elucidate deductions of the subsistence of objects, and of logical space as an infinite totality.
\end{abstract}

\section{Introduction}

The concept of a transcendental deduction is most closely associated, of course, with the philosopher Kant. In his monumental Critique of Pure Reason, for instance, Kant takes it as given that we have various kinds of experience (e.g., of space and time), as well as knowledge (e.g., arithmetical, geometrical, causal). He then moves on to ask how experiences and judgments of these sorts are possible. Whatever the necessary conditions of the possibility of such experiences and judgments are, Kant thinks, can be inferred to be true on the grounds of transcendental arguments. As Derek Pereboom explains:

Among Immanuel Kant's (1724-1804) most influential contributions to philosophy is his development of the transcendental argument. In Kant's conception, an argument of this kind begins with a compelling premise about our thought, experience, or knowledge, and then reasons to a conclusion that is a substantive and unobvious presupposition and necessary condition of this premise. (2014) 
In his Tractatus, Wittgenstein can fruitfully be understood as undertaking similar though distinct transcendental deductions. In particular, where Kant takes it as given that we have certain kinds of experience, as well as knowledge, and then asks how they are possible, Wittgenstein takes it as given that language has sense, and then seeks to deduce, transcendentally, the conditions of its sense.

In conversation with his student Desmond Lee, sometime in 193031, Wittgenstein made the following, tantalizing remark about TLP 1.12, which provides integral insights into certain crucial conditions of sense which Wittgenstein thought were implied transcendentally by the fact that propositions evidently have sense:

For the totality of facts determines both what is the case, and also all that is not the case. This is connected with the idea that there are elementary propositions, each describing an atomic fact, into which all propositions can be analysed. This is an erroneous idea. It arises from two sources. (1) Treating infinity as a number, and supposing that there can be an infinite number of propositions. (2) Statements expressing degrees of quality. This is red contradicts This is white. But the theory of elementary propositions would have to say that if $\mathrm{p}$ contradicts $\mathrm{q}$, then $\mathrm{p}$ and $\mathrm{q}$ can be further analysed, to give e.g. r, s, t, and v, w, and $\sim \mathrm{t}$. The fact is selfsufficient and autonomous. (King and Lee, 1980, p. 120)

In this paper, I will endeavor to explicate Wittgenstein's remarks in this quotation, and will focus in particular on the ways in which they shed light upon his deployment of transcendental deductions, in an effort to demonstrate key aspects of Tractarian semantics, metaphysics, and philosophy of mathematics. I will explicate Wittgenstein's deductions of: (a) the logical independence of elementary propositions, of (b) the subsistence of simple objects, of (c) the closed but infinite character of logical space, and of (d) that infinity is a number. I will argue that what are identified in the remark to Desmond Lee as two sources of the idea that all propositions are truth-functions of elementary propositions (i.e., (a) the logical independence of elementary propositions, and (d) that infinity is a number), are in fact critical presuppositions arrived at via a series of transcendental deductions, a series which leads from the thesis of extensionalism, to various significant and unobvious conclusions. More specifically, extensionalism as understood by Wittgenstein presupposes (a), and thus (b), and it also presupposes (c) as well as (d). Moreover, (b) and (c) each presuppose (d). While (d) is mentioned specifically in the remark to Desmond lee, the independence thesis' contained in (a) is alluded to therein when Wittgenstein says that the fact is 'self-sufficient and autonomous'.

Wittgenstein's transcendental deductions thus have the following, 'only if' conditional structure: 
Premise One: (e)xtensionalism $\rightarrow(((a \& c) \& d) \&(((a \rightarrow b) \&(b \rightarrow d))$ $\&(\mathrm{c} \rightarrow \mathrm{d})))$

Premise Two: (e)xtensionalism (by Universalization from bipolarity as a condition of sense)

$\therefore$ (a \& b) \& (c \& d) (by Modus Ponens, conjunction introduction, commutation, association)

In the context of this inference, we are not trying to prove (a), (b), (c), and (d), so much as we are showing that (a), (b), (c), and (d) are presupposed in various ways by extensionalism. Hence, in essence Premise One says: 'extensionalism only if (a), (b), (c), and (d).' The truth of (d), in particular, is logically 'overdetermined' in the sense that it is required by (b), (c), as well as (e). (d) is presupposed by extensionalism, and by several other things presupposed by extensionalism. This crucial role played by (d) may explain why Wittgenstein places specific emphasis on it within the remark to Desmond Lee.

As displayed within Premise Two, Wittgenstein sees extensionalism, simply, as a demonstrably justifiable generalization of bi-polarity, or the determinacy of sense, as a significance constraint on propositions. If the essence of propositions is bi-polarity, then the essence of all propositions is bi-polarity, apparent counter-examples (such as generality, and propositional attitude ascriptions) notwithstanding. Using ' $\mathrm{p}$ ' as a dummy constant, the relevant inference can be displayed informally as follows:

$\mathrm{p} \mathrm{v} \sim \mathrm{p}$ (bi-polarity)

$\therefore$ (p) $\mathrm{p} v \sim \mathrm{p}$ (by Universalization (or Universal Quantifier Introduction)) (i.e., If any proposition is bi polar, then every proposition is.)

Bi-polarity as a significance constraint on propositions, or as a condition of sense, has its origin for Wittgenstein in Russell's reflections upon propositional significance in Principia Mathematica, as well as in his own devastating criticisms of Russell's multiple relation theory of judgment in May-June 1913. It is well known that Russell abandoned his proposed book Theory of Knowledge in response to Wittgenstein's criticisms, levelled in stages over the course of May-June 1913 as Russell was furiously composing manuscript chapters and in turn showing Wittgenstein the crucial parts thereof. While there remains scholarly controversy over what precisely the nature and broader significance of these criticisms were for Russell, Wittgenstein's 'exactly expressed' objection in a June 1913 letter provides crucial insight into these criticisms, and their role in setting Wittgenstein along a trajectory to embracing bi-polarity, extensionalism, and anything implied by them, as conditions of sense. The crucial passage from that June 1913 letter reads as follows: 
I can now express my objection to your theory of judgment exactly: I believe it is obvious that, from the prop[osition] 'A judges that (say) $\mathrm{a}$ is in the Rel[ation] R to b', if correctly analysed, the prop[osition] 'aRb.v. aRb' must follow directly without the use of any other premiss. This condition is not fulfilled by your theory. (Wittgenstein, 1995, p. 29)

Notably, here Wittgenstein is not so much introducing Russell to a significance constraint upon propositional understanding of which he was previously unaware, so much as he is simply reminding Russell of this constraint on propositional understanding and suggesting that Russell's multiple relation theory does not meet it. This is evident from the fact that, in Principia Mathematica, Russell himself identifies this same basic significance constraint in relation to his theory of types. With reference to ${ }^{\star} 13.3$ in particular Russell writes:

The following proposition is useful in the theory of types. Its purpose is to show that, if $\alpha$ is any argument for which ' $\varphi \alpha$ ' is significant, i.e., for which we have $\varphi \alpha \mathrm{v} \sim \varphi \alpha$, then

' $\varphi x$ ' is significant when, and only when, $\mathrm{x}$ is either identical with $\alpha$ or not identical with

a. It follows (as will be proved in ${ }^{\star} 20.81$ ) that, if ' $\varphi \alpha$ ' and ' $\psi \alpha$ ' are both significant, the

class of values of $\mathrm{x}$ for which ' $\varphi \mathrm{x}$ ' is significant is the same as the class of those for

which ' $\psi \alpha$ ' is significant, i.e., two types which have a common member are identical.

(Russell and Whitehead, 1910-13/1997, p. 172)

Griffin (1985, 1985-86) and Sommerville (1979) argue that when Wittgenstein referred to a supplementary premise in the June 1913 letter quoted above, he was referring to a dyadic analogue of ${ }^{\star} 13.3$, which Russell hoped to deploy (in the most basic, illustrative case of a dyadic, first order judgment) as a significance constraint on judgment in order to exclude the possibility of nonsense judgments. This reading is certainly consistent with Wittgenstein's later remark in the Tractatus that 'a correct theory of judgment must make it impossible to judge nonsense. Russell's theory does not fulfill this requirement.' (TLP 1974, 5.5422) ${ }^{1}$

However, the details of Wittgenstein's criticism are complex, controversial, and need not concern us here. ${ }^{2}$ For our purposes what is important to note

1 When I wish to refer specifically to the 1974 Pears/McGuinness translation, I will use 'TLP 1974', while when I wish to refer specifically to the 1922 Odgen translation, I will use 'TLP 1922.' When I wish to refer indifferently to both, I will use 'TLP.'

2 For more detailed discussion of the scholarly controversy concerning Wittgenstein's objections and their effects on Russell, see Connelly (2011-12, 2014, 2015 (pp. 49-76)), Pincock (2008), Hanks (2007), and Stevens (2003, 2004). 
is that, in the lead up to his composition of the Tractatus, Wittgenstein, following Russell in Principia Mathematica, viewed bi-polarity as a condition of sense upon propositions. In other words, if a proposition ' $p$ ' had sense, then ' $\mathrm{p} v \sim \mathrm{p}$ ' inevitably followed from it. The inference to Premise Two within the informal argument above simply extends this point by insisting that if it is true of any proposition (bipolarity), then it is true of every proposition (extensionalism).

However, Wittgenstein describes extensionalism as 'an erroneous idea' in the remark to Desmond Lee because, as he began to have doubts about the independence thesis for elementary propositions, and as his views about infinity evolved, he came to see it as indefensible. In other words, Wittgenstein thought that extensionalism transcendentally implied (because it presupposed) certain views about elementary propositions, and about infinity, and when it became clear that these views could not hold, it became clear that extensionalism could not hold either. Wittgenstein's principal reason for coming to doubt the independence thesis was the colour exclusion problem alluded to in the remark to Desmond Lee. ${ }^{3}$

His views about infinity are more complex, but the denial that infinity is a number reflects a shift towards the finitistic constructivism characteristic of Wittgenstein's middle period (see Rodych, 2011). In that context, Wittgenstein came to see infinity as 'potential' as opposed to 'actual.' As he explained in Cambridge lectures from March 1930: 'Infinity is a property of a law, not of an extension...Word "infinite" not a numeral. It occurs in connection with "possible". (Stern et al 2016, pp. 32-33). To say that the natural numbers are infinite, in other words, is not to say that there is a very huge, transfinite number, 'infinity', at the limit of the natural number series, which designates the size (or cardinality) of the 'extension' (or membership) of the set of natural numbers. It is instead to say that the natural number series is indefinitely expansible, that it is governed by a general law according to which it is always possible to produce a successor to any previously constructed natural number, by simply adding ' 1 ' (more on this in section 2 ).

In any case, as a result of these concerns, Wittgenstein ultimately abandoned extensionalism, and the correlated thesis of determinacy of sense. The present discussion aims to shed light on precisely why these assumptions were so important to Wittgenstein's extensionalism, that he abandoned it in light of his concerns and changing views about them. To that end, (e) will be the subject of section 2, while the deduction of (a) will be the subject of section 3, of (b) the subject of section 4, and of (c) the subject of section 5 . As we shall see, several, interrelated deductions of (d) will also come up at various, crucial points in the discussion.

3 For a more detailed examination of the colour exclusion problem and the role it played in Wittgenstein's coming to reject the Tractarian logical system, see Connelly (2015, pp. 123-6). 
That there exist significant, thematic 'family resemblances' between Wittgenstein's philosophy, and that of Kant, is not a novel idea, having been developed and defended in greater detail (and in diverse ways) by Stenius (1960, pp 214-226), Hacker (1972), and Pears (1987), among others. ${ }^{4}$ Stenius in particular anticipated the notion that Wittgenstein deploys transcendental deductions (pp. 218-220) in the service of a project which bears significant similarities to, as well as crucial distinctions from Kant's. Succinctly, while Kant seeks to resolve philosophical problems through a critical investigation into the scope, limits, and conditions of possible experience and knowledge, Wittgenstein seeks to do the same by investigating the limits and conditions of sense, intelligible language, and thought.

Unfortunately, it is beyond the scope of this paper to critically assess, or defend a position regarding, the broader scholarly controversy concerning the nature and extent of affinities between Wittgenstein's philosophy (early and late), and that of Kant. My more modest goal will be to illuminate Wittgenstein's deployment of one specific feature of the Kantian methodology, namely transcendental deductions, in the demonstration of key elements within his early, Tractarian, philosophical perspective. If, in undertaking that task, this paper manages to shed light on these broader debates, I would consider that a welcome, auxiliary result.

\section{Extensionalism (e)}

In his Tractatus, Wittgenstein arrives at extensionalism via a generalization of bi-polarity. In other words, Wittgenstein endeavors to show, first, that everything which is a proposition is a truth-function of the bi-polar, elementary propositions, and second, that nothing else is a proposition. Hence he explains that:

The existence of a general propositional form is proved by the fact that there cannot be a proposition whose form could not have been foreseen (i.e., constructed). The general form of a proposition is: This is how things stand. Suppose I am given all elementary propositions: then I can ask what propositions I can construct out of them. And there I have all propositions, and that fixes their limits. Propositions comprise all that follows from the totality of all elementary propositions (and, of course, from its being the totality of them all). (Thus, in a certain sense, it could be said that all propositions were generalizations of elementary propositions.) (TLP 1974, 4.5-4.52)

When Wittgenstein speaks here of the construction of all propositions out of all elementary propositions, he is, as noted by Russell (ibid., pp. xv-

$4 \quad$ For a dissenting view, see Williams (1990) 
xvii), alluding to Sheffer's proof 'that all truth-functions of a given set of propositions can be constructed out of...not-p and not-q.' (ibid., p. xv) The generalization of this proof to the thesis of extensionalism rests on two additional assumptions. These are identified by Russell in his introduction (ibid., p. xvii). The first is that general (i.e., quantified) propositions are equivalent to truth-functions of elementary propositions, specifically conjunctions and disjunctions (i.e., truth-functional expansions). The second is that nothing other than a truth-function of an elementary proposition is a proposition, appearances notwithstanding.

That nothing other than a truth function of an elementary proposition is a proposition, Wittgenstein demonstrates primarily by providing analyses of various apparent counter-examples. The most conspicuous of these is Wittgenstein's eliminative analysis of propositional attitude ascriptions at TLP 5.542. However, TLP 5.542 is one of the most notoriously enigmatic passages in the Tractatus, and a detailed treatment of it would take our discussion too far afield. More interesting for our purposes is Wittgenstein's treatment of general, that is quantified, propositions.

Integral to Wittgenstein's treatment of generality is his articulation of the 'general form of a truth-function' at TLP 6. The general form of a truth function, (in symbols $[\bar{p}, \bar{\xi} \mathrm{N}(\bar{\xi})]$ ) specifies a procedure whereby all molecular as well as general propositions may be expressed via a limited number of successive applications of a single operator, $\mathrm{N}$, to selections of elementary propositions. What Wittgenstein's symbol for the general form of a truth-function tells us is that we should begin with all sentence letters (symbolized by $\bar{p}$ ), take a selection of those (symbolized by $(\bar{\xi})$, and then apply $\mathrm{N}$ to them (like so: $\mathrm{N}(\bar{\xi})$ ), to arrive at $\mathrm{N}$-expressed ${ }^{5}$ truth-functions of the elementary propositions symbolized by the selected sentence letters. According to Wittgenstein, all meaningful propositions may be expressed through variations upon this same basic procedure. In operating on selections of elementary propositions (and, successively, on their truth-functions) $\mathrm{N}$ functions similarly to joint negation (i.e., $\sim \mathrm{p} \& \sim \mathrm{q}$ (expressed in $\mathrm{N}$ notation as $\mathrm{N}(\mathrm{p}, \mathrm{q}))$ ) except that it may apply not only to two arguments, but to an indefinite number of arguments from 1, to an infinite number of arguments. To express ordinary negation, for example, we would simply apply $\mathrm{N}$ to a single elementary proposition, e.g., $\mathrm{p}$, like so $\mathrm{N}(\mathrm{p})$. To express the conjunction of $\mathrm{p}$ and $\mathrm{q}$, by contrast, we would apply $\mathrm{N}$, successively, first to each of $\mathrm{p}$ and

5 The term ' $\mathrm{N}$-expressed' simply refers to the appearance that truth-functions have when they are constructed using the $\mathrm{N}$ operator exclusively, as opposed to any other combination of truth-functional connectives, such as the ampersand (conjunction), the tilde (negation), or the wedge (disjunction). The truth-function known as joint negation may therefore be expressed using the ampersand and the tilde as ' $\sim \mathrm{p} \mathrm{\&} \sim \mathrm{q}$ ', or using the $\mathrm{N}$ operator as ' $\mathrm{N}(\mathrm{p}, \mathrm{q})$ '. The truth-function in question is said to be ' $\mathrm{N}$-expressed' in the second case but not the first. 
$\mathrm{q}$, and then place each of these $\mathrm{N}$ expressions under an additional iteration of $\mathrm{N}$ like so: $\mathrm{N}(\mathrm{N}(\mathrm{p}), \mathrm{N}(\mathrm{q}))$. To express the disjunction of $\mathrm{p}$ and $\mathrm{q}$, we would apply $\mathrm{N}$ successively first to (p, q), and then apply an additional iteration of $\mathrm{N}$ to this $\mathrm{N}$ expression, like so: $\mathrm{N}(\mathrm{N}(\mathrm{p}, \mathrm{q})$ ). Since conditional statements are true whenever either their antecedents are false or their consequents are true, $\mathrm{p} \rightarrow \mathrm{q}$ is equivalent to $\sim \mathrm{p} v \mathrm{q}$ which may be expressed in Wittgenstein's $\mathrm{N}$ notation as: $\mathrm{N}(\mathrm{N}(\mathrm{N}(\mathrm{p}), \mathrm{q}))$.

By allowing $\mathrm{N}$ to take an infinite number of arguments, moreover, and by allowing those arguments to be each of the infinite number of substitution instances of a propositional function such as $\mathrm{fx}$, for example, we may then use $\mathrm{N}$ to express something equivalent to Russellian quantification. As Wittgenstein explains at TLP 5.52, for instance, 'if $\xi$ has as its values all the values of a function $\mathrm{fx}$ for all values of $\mathrm{x}$, then $\mathrm{N}(\bar{\xi})=\sim(\exists \mathrm{x})$.fx.' In other words, if we substitute each of an infinite number of individual constants for $\mathrm{x}$ in $\mathrm{fx}$, and then place each of the infinite number of elementary propositions which result within the brackets under the scope of the $\mathrm{N}$ operator, like so: $N(f a, f b, f c, f d, \ldots, f \omega)$ (where ' $\omega$ ' stands for the infinitieth and final constant on the list), then we will thereby express something that is equivalent to the negation of $(\exists x) . f x$. To express the equivalent of $(\exists x) \cdot f x$, then, we need simply to apply an additional ' $\mathrm{N}$ ' to the front of this $\mathrm{N}$ expression in succession, like so: $\mathrm{N}(\mathrm{N}(\mathrm{fa}, \mathrm{fb}, \mathrm{fc}, \mathrm{fd}, . . \mathrm{f} \omega))$.

Like $(\exists \mathrm{x}) . \mathrm{fx}, \mathrm{N}(\mathrm{N}(\mathrm{fa}, \mathrm{fb}, \mathrm{fc}, \mathrm{fd}, . . \mathrm{f} \omega))$ is equivalent to a truth-functional expansion, a disjunction which takes each of an infinite number of substitution instances of the propositional function $\mathrm{fx}$, as disjuncts. The equivalent truthfunctional expansion can thus be given in the form of a disjunction as follows: fa $\mathrm{v} f \mathrm{v} v \mathrm{fc} \mathrm{v} f d \mathrm{v} \ldots \mathrm{v} f \mathrm{f}$ (where ' $\omega$ ' again, stands for the infinitieth and final individual constant on the list). Above we saw how to express the conjunction of $\mathrm{p}$ and $\mathrm{q}$ using the $\mathrm{N}$ operator, and from this it is easy to see how the $\mathrm{N}$ operator may be used to express something equivalent to universal quantification. We may express $(\forall \mathrm{x}) \mathrm{fx}$, for example, by using $\mathrm{N}$ to express something equivalent to the conjunction of each of the substitution instances of $\mathrm{fx}$, as follows: $\mathrm{N}(\mathrm{N}(\mathrm{fa}), \mathrm{N}(\mathrm{fb}), \mathrm{N}(\mathrm{fc}), \mathrm{N}(\mathrm{fd}), \ldots, \mathrm{N}(\mathrm{f}())$ ). This $\mathrm{N}$-expression is then equivalent to the following, conjunctive truth functional expansion: $\mathrm{fa} \& \mathrm{fb} \& \mathrm{fc} \& \mathrm{fd} \ldots \& \mathrm{f} \omega$. Multiple, and mixed multiply general propositions of the predicate calculus, we will then handle by using $\mathrm{N}$ to express the equivalent conjunctions (e.g., $(\forall \mathrm{x})(\forall \mathrm{y})$ Fxy), disjunctions (e.g., $(\exists \mathrm{x})(\exists \mathrm{y})$ $\mathrm{fxy})$, conjunctions of disjunctions (e.g., $(\forall \mathrm{x})(\exists \mathrm{y})$ Fxy), as well as disjunction of conjunctions (e.g., $(\exists \mathrm{y})(\forall \mathrm{x})$ Fxy)). ${ }^{6}$

As Fogelin notes, (1982, pp. 125-6, 1987, p. 81) it is crucial to the success of these constructions, however, that the lists of elementary propositions to which we apply the $\mathrm{N}$ operator must be limited. Otherwise, we will never

6 For a more detailed exposition of these constructions, see Connelly (2017, pp. 19-24). 
be able (in the context of universal quantification, for example) to complete the required list of $\mathrm{N}$ expressions inside the brackets, before moving on, in succession, to apply the final operation of $\mathrm{N}$ which serves as the sentence's main logical operator, and takes as its scope the rest of the sentence. So expressed using the $\mathrm{N}$ operator, as we saw, universal quantification has the following form: $\mathrm{N}(\mathrm{N}(\mathrm{fa}), \mathrm{N}(\mathrm{fb}), \mathrm{N}(\mathrm{fc}), \mathrm{N}(\mathrm{fd}), \ldots, \mathrm{N}(\mathrm{f} \omega))$. In order to complete this $\mathrm{N}$ expression by applying the $\mathrm{N}$ furthest to the left, which is the main logical operator of the sentence, we must first complete the list of $\mathrm{N}$ expressions inside the brackets under its scope. But it would be impossible to do that, even in principle, unless the list of elementary propositions, each of which occurs under an iteration of $\mathrm{N}$, is limited. ${ }^{7}$

This explains why Wittgenstein asserts, at TLP 5.32, that 'All truthfunctions are results of successive applications to elementary propositions of a finite number of truth-operations.' This claim is the conclusion of a transcendental deduction, from bi-polarity as a condition of sense upon propositions, to a conception of general propositions as constructible via a limited number of successive applicatons of $\mathrm{N}$, upon a limited number of elementary propositions. By 'finite', (endlichen) in this case, Wittgenstein is not referring to the cardinality of a set of applications, but instead simply means 'limited' (as opposed to 'endless' or unendlichen) and refers to the completion of an ordered series of operations (of possibly infinite cardinality). ${ }^{8} \mathrm{He}$ thereby implies that infinite domains, along with the infinite lists of elementary propositions which figure within truth-functional expansions, must constitute limited totalities. These notions presuppose the claim that (d) infinity is a (countable, actual) number, which as we saw was identified in conversaton with Desmond Lee quoted in section 1.

In his introduction to the Tractatus, Russell (TLP 1974, p. xxiii) identifies an alleged lacuna within Wittgenstein's logical system, relating specifically to transfinite number. Briefly exploring this lacuna will help us to better understand what Wittgenstein means by the claim that infinity is a number', made in relation to the 'infinite number' of propositions alluded to in the remark to Desmond Lee. The lacuna has to do with the fact that, in the Tractatus, Wittgenstein speaks of 'infinity' as if it were one number and neither identifies nor discusses any additional, transfinite numbers. Yet, since selections of elementary propositions stand in one-to-many relations both to their truth-possibilities, and truth-functions, then if there exist infinite totalities of elementary propositions (as was presumed above in our explication

7 Geach (1981, 1982), as well as Rogers and Wehmeier (2012), have proposed notational alternatives designed to circumvent these and other issues identified by Fogelin with regards to the expressive completeness of Wittgenstein's $\mathrm{N}$ operator. For a more detailed critical consideration of these alternatives, see Connelly (2017).

8 See Connelly (2017, pp. 5-10) for a more deep and detailed discussion and defence of this claim. 
of operator $\mathrm{N}$ ), this might seem to require the existence of higher, infinite totalities with tranfinite cardinalities. So that leaves the situation somewhat ambiguous with regards to what, exactly, Wittgenstein means by 'infinity', particularly in relation to the infinite totalities of elementary propositions appealed to in the constructions of various $\mathrm{N}$-expressions, above.

Wittgenstein later sheds light on these issues in his November 1932 Cambridge lectures when he speaks of a 'most important mistake in the Tractatus'. (Stern et al., 2016, p. 216) There he criticizes his Tractarian account of the expressive completeness of $\mathrm{N}$ on the grounds that it involves a fallacy akin to 'muddling up a sum with the limit of a sum'. (ibid., p. 217) In other words, a sum, like the construction of an $\mathrm{N}$-expression according to the method we described above, has an end. The limit of a sum, by contrast, is something a series may ever more closely approximate, but never reach.

For example, the sum $1 / 2+1 / 4+1 / 8+1 / 16+\ldots$ approaches (though it never reaches) a limit, namely 1 . By contrast, the sum $57+68$ comes to an end and has an answer, namely 125 . The two sorts of sums are very different, in that the series of numbers put together in the latter is complete whereas in the former the series is endless. In the first case, the numbers just keep getting smaller and smaller, and the summation approaches its limit more closely and closely, but it never reaches that limit.

When he speaks of muddling up the idea of a sum with that of the limit of a sum, Wittgenstein seems to be saying that, at the time of authoring the Tractatus, he mistakenly thought $\mathrm{N}$ could replace quantification by successively operating upon infinite, but nevertheless completed lists of elementary propositions, as if an infinite conjunction of negations was more or less analogous to $57+68$, only longer. He later came to realize, however, that it does not in fact make sense to think of infinite lists of elementary propositions as completed, any more than it makes sense to think of a series approaching a limit as completed.

These observations strongly suggest that, at the time of authoring the Tractatus, Wittgenstein implicitly viewed infinity, especially as it relates to the totality of elementary propositions, through the lens of the concept of a limit ordinal.' A 'limit ordinal' is an infinite number to which one can add any finite, natural number without altering its cardinality. ${ }^{9}$ So, for instance, the first limit ordinal, $\omega$, has the same cardinality as $\omega+1$, or $\omega+2$, or $\omega+1002$. Moreover, $\omega$ is identified as the ordinal number of the infinite totality of all natural numbers. Thus, if $\omega$ represents the number of elementary propositions, then we can keep adding finite numbers of elementary propositions to a list, while nevertheless treating the list as a limited total.

These features of a limit ordinal can be made somewhat more intuitive by reflecting on the thought experiment of 'the Hilbert hotel, ${ }^{10}$ which is a hotel

9 See Steinhart (2009, pp 163-8)

10 See Steinhart (2009, pp 158-9) 
that contains an infinite number of rooms, and is full of an infinite number of guests, yet busloads of new people keep showing up and the proprietor is able to find and assign rooms for those people by moving the current tenants to new rooms according numerical patterns. So, for instance, to make room for new guests, the proprietor of the hotel would take a selection of the room numbers $1-\omega$, say the even numbers $2,4,6,8$, and so on, and put the new guests in these now empty rooms after moving the prior guests from those rooms into new rooms. Even though the hotel is full, we can keep finding new rooms for old tenants to move to so that new tenants can replace them. And the cardinal number of rooms in the hotel will remain the same once the old tenants move into the new rooms.

This procedure exhibits the fallacy Wittgenstein alluded to when he talked about muddling up a sum with the limit of a sum. If you can keep admitting new guests to the hotel, then it is not really full and if you can keep admitting them ad infinitum then the totality of rooms is not a countable totality. If a hotel truly had an infinite number of rooms, then it could not be full, and the proprietor would not have to move any guests in order to make room for new tenants. Understood in this alternate sense, infinity is 'potential' rather than 'actual.' To say that a hotel had an infinite number of rooms would just be to say that it had an infinite potential of available space, perhaps in the sense that new rooms could be instantly fabricated any time a new guest showed up (just as a successor may instantly be fabricated for any natural number by simply adding ' 1 '). Such a hotel might exist in virtual reality, for example.

Yet at the time of authoring the Tractatus, as we have suggested, Wittgenstein was committed to the actual infinite, and to the notion that elementary propositions constitute an infinite yet completed totality. No matter how many elementary propositions we operate upon in constructing our $\mathrm{N}$-expressions, that number, even if infinite, will always be countable, and our $\mathrm{N}$-expression will be constructible in a limited series of steps. (TLP 5.32) This seems to entail that Wittgenstein was at least implicitly committed to the claim that the totality of elementary propositions had the same cardinality as the natural numbers, and thus that of the limit ordinal $\omega$, namely $\aleph_{0}$.

By the time he reached his middle period when he made the remark to Desmond Lee quoted in section 1, however, Wittgenstein had come to think that the idea of a countably infinite totality (or actual, completed infinity) was a confused idea, which is why he identifies the assumption that (d) 'infinity is a number', as one of the erroneous ideas required by Tractarian extensionalism. This may explain, in part, why in Remarks on the Foundations of Mathematics (Wittgenstein 1978/ 1996, p. 135), he is critical of the idea that Cantor's diagonalization argument proves the existence of a transfinite number, $\aleph_{1}$, which is of greater cardinality than $\aleph_{0}$. But at the time of authoring the Tractatus, he seems to have more or less uncritically 
derived the notion of an infinite totality from Cantor, perhaps via Russell. ${ }^{11}$ Moreover, he seems to have implicitly deployed the concept of a limit ordinal, $\omega$, to account for how $\mathrm{N}$ may be used to recover Russellian quantification over countably infinite domains. This explains why Moore records Wittgenstein as saying, in Cambridge lectures from November 1932, that: 'In my book I supposed that $(\exists \mathrm{x}) \mathrm{fx}=\mathrm{fa} \mathrm{v} \mathrm{fb} \mathrm{v} \mathrm{fc} \&$ so on was of laziness, when it wasn't' (Stern et al, 2016, p. 217). And it also explains why Wittgenstein writes in the Big Typescript that:

My understanding of the general proposition was that $(\exists \mathrm{x}) . \mathrm{fx}$ is a logical sum, and that although its terms weren't enumerated there, they could be enumerated (from the dictionary and the grammar of language). (2005, p. 249)

Existential and universal quantifications, as we have seen, would be reduced to the corresponding, $\mathrm{N}$-expressed, truth-functional expansions, and in that context $\mathrm{N}$ would operate on countably, infinitely long, but enumerable in principle and thereby completed lists of elementary propositions. If we use 'and so on', or '...' in formulating these constructions, then according to Wittgenstein's early view this merely indicates the irrelevant psychological fact that writing down each and every one of the terms in the construction is too time consuming, or boring, or laborious. But it would nevertheless remain possible, in principle, to write the construction down in its totality, in a limited, and successive series of steps.

\section{Independence (a)}

In section 2 we saw how Wittgenstein sought to extend bi-polarity as a condition of sense on propositions, to extensionalism as a thesis about the truth-functional nature of all propositions, including ostensibly general propositions. In section 3 we will now see how, according to Wittgenstein, both bipolarity and extensionalism presuppose logical independence as a thesis about elementary propositions. Wittgenstein describes the relevant transcendental deduction as follows:

If the world had no substance, then whether a proposition had sense would depend upon whether another proposition was true. In that case we could not sketch any picture of the world (true or false). (TLP 1974, 2.0211-2.0212)

11 Evidence for this claim can be found in Russell's (1919/1983) Introduction to Mathematical Philosophy, where Russell makes it clear (pp. 80, 89-90) he believes that two series can each be infinite, and equivalent in size, and yet one can be placed after the end of the other to create a new series of infinite size. 
Truth be told, Wittgenstein is undertaking transcendental deductions of two distinct theses in this passage: a) the independence thesis for elementary propositions, and b) the subsistence of metaphysically simple objects. Since b) will be the subject of section 4 , however, let us focus on a) for the time being. Wittgenstein's point here is actually quite easy to demonstrate, by considering a rudimentary truth-table, say the truth-table for $\mathrm{p} \& \mathrm{q}$ ( or $\mathrm{N}(\mathrm{N}(\mathrm{p}), \mathrm{N}(\mathrm{q}))$.

\begin{tabular}{|c|c|c|c|}
\hline $\mathrm{p}$ & $\mathrm{q}$ & $\mathrm{p} \mathrm{\&}$ & \\
\hline $\mathrm{T}$ & $\mathrm{T}$ & $\mathrm{T}$ & 1 \\
\hline $\mathrm{T}$ & $\mathrm{F}$ & $\mathrm{F}$ & 2 \\
\hline $\mathrm{F}$ & $\mathrm{T}$ & $\mathrm{F}$ & 3 \\
\hline $\mathrm{F}$ & $\mathrm{F}$ & $\mathrm{F}$ & 4 \\
\hline
\end{tabular}

As per extensionalism, $\mathrm{p} \& \mathrm{q}$ is in the most basic case, a truth-function of the elementary propositions $\mathrm{p}$ and $\mathrm{q}$. In particular, it is a function which yields the value ' $\mathrm{T}$ ' when both $\mathrm{p}$ and $\mathrm{q}$ take the value ' $\mathrm{T}$ ', and it false otherwise. So, when is it 'otherwise'? Well, when for example $\mathrm{p}$ is ' $\mathrm{T}$ ' and $\mathrm{q}$ is 'F.' (row 2) But if the independence thesis for elementary propositions were false, then the sense of $p$ could theoretically depend on the truth of $q$ and in that scenario, this line of the truth-table would be ruled out. In fact, both rows 2 and 4 would be ruled out, since, in the original table, $\mathrm{q}$ is false on each of those rows.

\begin{tabular}{|c|c|c|c|}
\hline $\mathrm{p}$ & $\mathrm{q}$ & $\mathrm{p} \& \mathrm{q}$ & \\
\hline $\mathrm{T}$ & $\mathrm{T}$ & $\mathrm{T}$ & 1 \\
\hline $\boldsymbol{?}$ & $?$ & $?$ & 2 \\
\hline $\mathrm{F}$ & $\mathrm{T}$ & $\mathrm{F}$ & 3 \\
\hline $\boldsymbol{?}$ & $?$ & $?$ & 4 \\
\hline
\end{tabular}

But if these two lines of the truth-table are ruled out, then the whole table and indeed the whole procedure of using truth-tables to provide the truth-conditions of molecular propositions, and thereby as a decision procedure for propositional and predicate logic, would be irreparably messed up. Extensionalism, the idea that all propositions are truth-functions of elementary propositions, thus entails independence. It presupposes, that is, the thesis that at the bottom level of analysis, elementary propositions must be capable of being either true or false, independently of the truth-values of other elementary propositions.

This explains why Wittgenstein came to see the problem of colour exclusion as such a devastating threat to the logical and semantic framework of his Tractatus, and why, in the conversation with Desmond Lee reproduced in section 1 , he identifies as imperative to the maintenance of extensionalism, 
the provision of an analysis upon which colour exclusion is reduced explicitly to contradiction (in his example, the contradiction would be between $t$ and $\sim \mathrm{t})$. For if one cannot show upon analysis that the conjunction of 'This is red' and 'This is white' contains a hidden contradiction, then the correct analysis of these two sentences must reveal at least two mutually incompatible elementary propositions, and that is incompatible with the independence thesis for elementary propositions. This is why Wittgenstein explains that:

Just as the only necessity that exists is logical necessity, so too the only impossibility that exists is logical impossibility. For example, the simultaneous presence of two colours at the same place in the visual field is impossible, in fact logically impossible, since it is ruled out by the logical structure of colour...It is clear that the logical product of two elementary propositions can neither be a tautology nor a contradiction. The statement that a point in the visual field has two different colours at the same time is a contradiction. (TLP 1922, 6.375-6.3751)

The correct analysis of the incompatibility characteristic of colour exclusion must terminate in an explicit contradiction between e.g., $t$ and $\sim t$, since by independence, two elementary propositions $t$ and p, e.g., cannot be incompatible.

That, moreover, Wittgenstein sees truth-tables as providing a decision procedure for propositional and predicate logic is evident from several remarks, all interrelated to his claim that '(i)t is the peculiar mark of logical propositions that one can recognize that they are true from the symbol alone', (TLP 6.113) or as he puts it at TLP 6.126 '(o)ne can calculate whether a proposition belongs to logic, by calculating the logical properties of the symbol'. According to Wittgenstein, logical propositions are tautologies, that is, molecular propositions in which elementary propositions are combined into structures which yield the value 'true' on all possible truthvalue assignments to their constituent elementary propositions. That these elementary propositions yield a tautology when combined in certain ways, shows that the molecular proposition which results from their combination possesses certain relevant, structural properties. As Wittgenstein explains: "The fact that the propositions " $p \rightarrow q$ ", "p", and "q", combined with one another in the form " $(p \rightarrow q)$. ( $p): \rightarrow:(q)$ ", yield a tautology shows that $q$ follows from $\mathrm{p}$ and $\mathrm{p} \rightarrow \mathrm{q}$ '. (TLP 6.1201) The proposition '( $\mathrm{p} \rightarrow \mathrm{q})$. (p): $\rightarrow:$ ( $\mathrm{q}$ )' is thus a form of proof (TLP 6.1264), which, since it is a tautology, allows us to infer $q$ from $\mathrm{p} \rightarrow \mathrm{q}$, and $\mathrm{p}$.

Aside from yielding a tautology when combined in this way, moreover, that $\mathrm{q}$ follows from $\mathrm{p}$ and $\mathrm{p} \rightarrow \mathrm{q}$ is also evident in the fact that no row of a truth-table containing columns for each of these propositions, assigns the value ' $\mathrm{T}$ ' to each of the premises ( $\mathrm{p} \rightarrow \mathrm{q}$ and $\mathrm{p}$ ) but assigns the value ' $\mathrm{F}$ ' to the conclusion (q) (the premises are indicated by ${ }^{*}$ and the conclusion by $\mathrm{C}$ ). Here we can see these two features of Modus Ponens side by side. 


\begin{tabular}{|c|c|c|c|c|}
\hline${\mathrm{p} \rightarrow \mathrm{q}^{*}}^{*}$ & $\mathrm{p}^{*}$ & $\mathrm{q} \mathrm{C}$ & $((\mathrm{p} \rightarrow \mathrm{q}) \& \mathrm{p}) \rightarrow \mathrm{q}$ & \\
\hline $\mathrm{T}$ & $\mathrm{T}$ & $\mathrm{T}$ & $\mathrm{T}$ & 1 \\
\hline $\mathrm{F}$ & $\mathrm{T}$ & $\mathrm{F}$ & $\mathrm{T}$ & 2 \\
\hline $\mathrm{T}$ & $\mathrm{F}$ & $\mathrm{T}$ & $\mathrm{T}$ & 3 \\
\hline $\mathrm{T}$ & $\mathrm{F}$ & $\mathrm{F}$ & $\mathrm{T}$ & 4 \\
\hline
\end{tabular}

Hence, according to Wittgenstein, 'it follows...that we can actually do without logical propositions; for in a suitable notation we can in fact recognize the formal properties of propositions by mere inspection of the propositions themselves' (TLP 6.122). Logic is thus, in its very nature, a truth-functional calculus that allows us to decide (among other things) when propositions are logical (i.e., tautologies), and, relatedly, which propositions follow from what others.

That Wittgenstein means these considerations to apply to the predicate in addition to the propositional calculus, moreover, is evident from his providing as an example of a tautology revealing structural properties, the fact that '( $\mathrm{x})$. fx: $\rightarrow$ : fa' is a tautology showing that 'fa' follows logically from '(x). fx.' (TLP 6.1201). As we have seen, at TLP 5.52 Wittgenstein indicates how one can use a truth-functional $\mathrm{N}$ notation, in order to express general propositions without using quantifiers (i.e., he shows how to eliminate quantifiers in favour of N). Specifically, Wittgenstein means to reduce all general propositions to $\mathrm{N}$-expressed truth-functional expansions of the propositional calculus, whose logical properties may then be evaluated via the corresponding, truth-tabular notation. Whether a human being could perform this evaluation is, from Wittgenstein's perspective, an irrelevant psychological question. Perhaps human beings need quantifiers to codify the relevant inferences in a way they can comprehend in a finite amount of time: '(p)roof in logic is merely a mechanical expedient to facilitate the recognition of tautologies in complicated cases'. (TLP 6.1262) But from a logical point of view, quantifiers amount to no more than a completely inessential short-hand notation for an $\mathrm{N}$-expressed truth-functional expansion. And a sufficiently powerful God or supercomputer could easily use the truth-tabular notation to calculate and so decide whether this $\mathrm{N}$-expressed truth-functional expansion was or was not a logical proposition.

\section{Substance and Objects (b)}

Earlier, I noted that TLP 2.0211-2.0212 contained two interrelated transcendental deductions. Recall that extensionalism is simply a generalization of the idea that being a true or false depiction of reality is the essence of propositional sense. In TLP 2.0211 Wittgenstein alludes to this generalization when he identifies two interrelated conditions upon which depend the 
possibility of sketching a true or false picture of the world (i.e., of the totality of all facts, not just any particular fact). We saw that the independence thesis was one condition of the possibility of extensionalism. But in this same passage, Wittgenstein also alludes to another condition of the possibility of extensionalism: substance. If the world had no substance, Wittgenstein insists, then the independence thesis could not hold. But if the independence thesis could not hold then extensionalism would not be viable either. Thus, substance can be deduced transcendentally from extensionalism.

But what precisely does Wittgenstein mean by substance, and why does he think it is entailed by the independence thesis for elementary propositions? Some light is shed on this question by the immediately preceding remark: 'objects make up the substance of the world. That is why they cannot be composite'. (TLP 1974, 2.021) If objects were composite, then they would be decomposable. But if they were decomposable, then the simple names which stand for them could potentially cease to have references. But if a name ceases to have a referent, then the proposition containing the name will cease to have a determinate truth-value, and will thus run afoul of the classical law of excluded middle. And since implying (an instance of) the law of excluded middle is a condition of sense on propositions, any 'proposition' containing an 'empty name' cannot really be a proposition. As Russell explains in 'On Denoting':

By the law of excluded middle, either 'A is B' or 'A is not B' must be true. Hence either 'the present King of France is bald' or 'the present King of France is not bald' must be true. Yet if we enumerated the things that are bald, and then the things that are not bald, we should not find the present King of France on either list. (1905, p. 485)

If the proposition 'A is B' is to have sense, then it must imply 'A is B or A is not B'. Since 'The present King of France is bald' does not seem to imply its own truth or falsity, its status as a proposition is at least prima facie dubious.

Of course, Russell's solution to this problem is to insist that 'the present King of France' is a really a description not a name or singular term. But Wittgenstein thinks this sort of 'descriptivist' approach will resolve the problem alluded to in the passage, only if such descriptions consist of complete descriptions, which could in principle be analysed down to the level of statements about the most basic, atomic constituents of the complexes so described. Hence he insists that:

Objects are simple. Every statement about complexes can be resolved into a statement about their constituents and into the propositions that describe the complexes completely. (TLP 1974, 2.02- 2.0201)

If such complete descriptions were not reducible to elementary propositions containing simple names standing for metaphysically simple, 
and so indecomposable objects, then statements about either complexes or objects could depend for their sense (i.e., their bi-polarity) upon other propositions attributing existence to those complexes or objects. But in that case, the sense of one proposition (e.g., Kripke is a logician) might depend upon the truth of another (i.e., Kripke exists), and that would violate the independence thesis for elementary propositions. ${ }^{12}$ As we have seen, however, the independence thesis for elementary propositions is, according to Wittgenstein, the sine qua non of extensionalism, and extensionalism is simply a generalization of bi-polarity as an essential condition of sense upon propositions. The subsistence of metaphysical simples can thus be deduced transcendentally from extensionalism, i.e., the determinacy of sense.

But how does this analysis engage with Wittgenstein's claim, in the remark to Desmond Lee, that 'infinity is a number' (d)? Here the idea that infinity is a number is implied by the fact that simple objects are the result of an infinite yet terminal division of everything complex down to its most basic, atomic constituents. In other words, if one divides any complex into its constituent parts, and those parts into their constituent parts and so on ad infinitum, the division will nevertheless terminate in basic constituents which cannot be further divided. These will be what is referred to by semantically simple names, and that an elementary proposition contains such names will be a necessary condition of sense. Wittgenstein calls these metaphysically simple constituents 'objects' by contrast with everything else in the world which is 'complex.' While complexes 'exist' according to Wittgenstein, because they are decomposable and so could fail to exist; objects 'subsist' because they are indecomposable and so cannot fail to subsist. The subsistence of metaphysically simple objects is thus presupposed in true or false assertions of the existence of complexes. In other words, substance is presupposed as a condition of sense both of elementary propositions describing atomic facts, but also of any 'world picture' consisting of truth-functions of those elementary propositions. The subsistence of metaphysically simple objects, (b), is thus presupposed by extensionalism (e), and in turn presupposes (d) the claim that infinity is a number since objects are simply what is left over, at the end, after everything that can be divided is divided into its constituent parts ad infinitum.

\section{Logical Space (c)}

In section 2 we examined how Wittgenstein intended to extend his claim about the bi-polarity of propositions, to extensionalism as a claim about the truth-functional character of all propositions, including general propositions.

12 This point is nicely developed by Pears (1987, pp. 126-7). Obviously, the use of the name 'Kripke' is merely illustrative. The same point can be made to apply to simple objects by considering the proposition pair: $\mathrm{Fa},(\exists \mathrm{x})(\mathrm{x}=\mathrm{a})$, where ' $\mathrm{a}$ ' is the name of a simple object. 
Given the idea that elementary propositions comprise an actual, completed infinity, as we saw, it was easy to envision how general propositions could be expressed via a limited number of successive applications of $\mathrm{N}$. We can now note some important implications of this construction, relative to Wittgenstein's intention to deploy truth-tables as a decision procedure for both propositional and predicate logic. If all propositions, including general propositions are expressible via a single, truth-functional operator, and if that truth-functional operator is, therefore, in principle eliminable in favour of truth-tabular representation, it is easy to see how one could use the truthtabular method to assess the truth-functional truth or truth-functional falsehood of any proposition, as well as the validity of any inference from one proposition, or set of propositions, to another proposition. In section 3 , however, we saw that this 'truth-tabular' picture of expressive completeness, and of entailment, presupposes the notion that elementary propositions are logically independent. If elementary propositions are not logically independent, then certain crucial lines of the truth-tables we use to express and to test propositions, will be ruled out.

If, however, infinity is a countable, actual number, and if elementary propositions are logically independent of one another, then all propositions are expressible via a terminal number of truth-operations, and there is in principle, at least, a complete (if very long) truth-table which lists the truthconditions of every meaningful proposition. On this assumption, a very powerful God, or supercomputer, say, might complete the truth-table listing the truth-conditions of every meaningful proposition, as well as complete a check as to whether any given proposition on the list followed from other propositions on the list. It could also complete a check with regards to any proposition on the list, whether that proposition was or was not a tautology (or a contradiction). And so the Tractatus would present a system which was both expressively complete, in principle, and which also provided a decision procedure, in principle, for propositional and predicate logic. Keep in mind, this is all hypothetical. If infinity were an acutal, countable number and if all elementary propositions were logically independent, then in principle what I have said above would present a conflict which Church's theorem, or the proof that there is no decision procedure for first order logical validity. (c.f. Fogelin, 1982 , p. 127) But infinity is not a number, elementary propositions are not logically independent, and that is why Wittgenstein eventually repudiated both of these claims by 1931 . So, there is no conflict.

However, if, on those assumptions, such a decision procedure were possible, this would have some important implications for logical space. In particular, it would imply that logical space, though infinitely large, must nevertheless be limited or totalized. It would have to contain an infinite number of negative and positive facts, and these would also have to be all of or the totality of facts. Logical space would have to be both boundless 
and endless, but also limited and closed. It would have to be infinitely fine in the sense of ultimately being made up of constituents which were the remainder after everything that could be divided was divided ad infinitum, but also all-encompassing in the sense that whatever could be constituted of such constituents would embody the totality of all possible facts. And these are precisely the ways we do find Wittgenstein characterizing logical space, at various junctures throughout the Tractatus. Wittgenstein notes for instance that:

The world is determined by the facts, and by these being all the facts. For the totality of facts determines both what is the case, and also all that is not the case. The facts in logical space are the world. (TLP 1922, $1.11-1.13$ )

But he also writes for instance that 'a spatial object must be lie in infinite (unendlichen) space'. (TLP 2.0131) It must, that is, lie in 'endless' or 'unending' space. Similarly, Wittgenstein characterizes logical space both as the 'infinite whole', (TLP 4.463) which is left undetermined by a tautologous assertion, but also as a 'limited whole', (TLP 6.45) viewed under the aspect of eternity, or timelessly. He claims moreover that logic, which is a mirror of the world, is a 'network' (TLP 5.511) that is both 'all-embracing', (ibid.,) but also 'infinitely fine.' (ibid.,)

Perhaps most interestingly in this connection, is Wittgenstein's characterization of logic as the study of a 'closed regular structure' or 'sphere' in which the answers to logical and philosophical questions are 'symmetrically combined':

The solutions of the problems of logic must be simple, since they set the standard of simplicity. Men have always had an intuition that there must be a sphere in which the answers to questions are symmetrically united-a priori-into a closed regular structure. A sphere in which the proposition, simplex sigillum veri, is valid. (TLP 1922, 5.4541)

For Wittgenstein, remember, logic is not simply the study of symbols in a book. It instead reveals the a priori logical form, or 'logical scaffolding', (TLP $3.42,4.023$,) of reality: 'the propositions of logic describe the scaffolding of the world.' (TLP 6.124) An important feature of the a priori logical scaffolding which Wittgenstein identifies at TLP 5.4541, then, is that it embodies a 'closed regular structure'(abgeschlossenen, regelmäßigen Gebilde) or 'closed regular shape', (shape $=$ Gebild $)$ akin to a sphere.

Such a conceptualization of logical space dovetails well with a Hertzian reading of Tractarian objects (see Bizarro, 2010), according to which the underlying substance of reality, that which provides the 'unalterable form' (TLP 2.023) of the world, are Hertzian 'material points' akin to geometrical, space-time coordinates. On this reading, simple, indivisible, geometrical, 
space-time coordinates are the substance, that is objects, of which the infinitely divisible, and infinitely large, but nevertheless limited totality of logical space is made up. On Wittgenstein's view, logical space is a symmetrical, and enclosed, infinitely divisible geometrical network which embodies the $a$ priori conditions of the possibility of all facts and propositions. It is an 'all embracing' and 'infinitely fine' network, or field, into which all of the atomic and molecular logical forms shown by propositional and logical signs are 'connected' (TLP 5.511) or interwoven. Propositional signs thus give the 'logical coordinates', (TLP 3.41) of a 'logical place' (TLP 3.411), and these 'agree' (ibid.,) with the coordinates of a 'geometrical place' (ibid.,) in which existence is possible. And this explains why Wittgenstein claims that:

Though a state of affairs that would contravene the laws of physics can be represented by us spatially, one that would contravene the laws of geometry cannot...geometry can obviously say nothing about the actual form and position of geometrical figures. But the network is purely geometrical, and all its properties can be given a priori. (TLP $3.0321,6.35)^{13}$

In other words, logic and geometry are together 'consistent' ${ }^{14}$ (TLP 3.411) in providing the a priori 'network', or 'scaffolding', (TLP 3.42) which makes possible the existence of states of affairs. Yet because logical and geometrical space constitute a space of possibility characterized essentially by the existence and non-existence of atomic facts, described completely by the totality of true and false elementary propositions, and because that space of possibility must be limited or closed if truth-tables are to give the determinate truth-conditions and truth-grounds of any truth-function of elementary propositions, logical and geometrical space as a whole must be given, if any meaningful elementary proposition is given: 'a proposition determines only one place...but nevertheless gives the whole of logical space. (TLP 3.42) ${ }^{15}$ Extensionalism, as a generalization of the bipolarity of elementary propositions, thus implicates the subsistence of an infinitely large, and infinitely divisible, but limited and totalized, closed regular structure for all negative and positive facts which are the case. In other words, it entails the subsistence of a limited but infinite, logical and geometrical scaffolding for the world.

\section{Conclusion}

In this paper, I set out to shed light on Wittgenstein's use of transcendental deductions in his endeavour to demonstrate key aspects of Tractarian semantics, metaphysics, and philosophy of mathematics. In particular,

13 Translation altered.

14 Translation altered.

15 Translation altered. 
I focused on two crucial claims which figured integrally within these transcendental deductions, each identified in conversation with Desmond Lee in 1931. Specifically, these claims were that of (a) the logical independence of elementary propositions, and (d) that infinity is a number. I showed how these crucial claims were demonstrated and deployed by Wittgenstein in the context of a series of transcendental deductions, which began with extensionalism as a generalized condition of sense on propositions, and which subsequently sought to demonstrate several significant, but unobvious presuppositions of that generalized condition of sense. In section 1, I explored the origins of this generalized condition of sense both in Russell's Principia Mathematica, and in Wittgenstein's 1913 critique of Russell's multiple relation theory of judgment. In section 2, explicated the role played by extensionalism within Tractarian logic and semantics, and showed how the expressive completeness of Wittgenstein's $\mathrm{N}$ operator presupposes the claim that infinity is an (actual, countable) number. In section 3, I then showed how the independence thesis for elementary propositions was to be deduced transcendentally from extensionalism. In section 4, I showed how the subsistence of simple objects was deduced from extensionalism and independence, and how this deduction also required the crucial assumption that infinity is a number. Finally, in section $5 \mathrm{I}$ drew out some implications of the thesis of extensionalism for the nature of logical space, and showed how the required characterizations of logical space are both textually well-founded, and depend the assumption that logical space is an infinite totality. As we saw, Wittgenstein consistently characterizes logical space both as an 'infinite whole' but also a 'limited whole.' $\mathrm{He}$ characterizes it as an 'infinitely fine network', but also as a 'closed regular structure.' These features explain how the logical forms of various elementary and molecular propositions can be interwoven into 'self-contained system' (Wittgenstein, 1974, 5.4541) in which logical and geometrical spaces agree. And they explain, finally, how any meaningful proposition or truth-function, whether elementary or molecular, infinite or finite, can be listed on a truthtable which explicates its determinate truth-conditions and truth-grounds.

\section{References}

Bizarro, Sara. (2010). 'A Hertzian Interpretation of Wittgenstein's Tractatus' Eidos 13: 150-165.

Connelly, James. (2011-12). 'On “Props”, Wittgenstein's June 1913 Letter, and Russell's "Paralysis."' Russell: The Journal of Bertrand Russell Studies, 31(2):141-66.

Connelly, James. (2014). 'Russell and Wittgenstein on Logical Form and Judgment: What did Wittgenstein Try that Wouldn't Work?' Theoria: A Swedish Journal of Philosophy, 80(3): 232-254. 
Connelly, James. (2015). Wittgenstein and Early Analytic Semantics: Toward a Phenomenology of Truth. Lanham, Maryland: Lexington Books.

Connelly, James. (2017). 'On Operator N and Wittgenstein's Logical Philosophy.' Journal for the History of Analytical Philosophy, 5(4): 1-26.

Fogelin, R.J. (1982). 'Wittgenstein's Operator N.' Analysis, 42: 124-127.

Fogelin, R.J. (1987). Wittgenstein, $2^{\text {nd }}$ Edition. London, UK: Routledge and Kegan Paul.

Geach, P.T. (1981). 'Wittgenstein's Operator N.' Analysis, 41: 168-70.

Geach, P.T. (1982). 'More on Wittgenstein's Operator N.' Analysis, 42: 127128.

Griffin, Nicholas. (1985). 'Russell's Multiple Relation Theory of Judgment.' Philosophical Studies, 47: 213-47.

Griffin, Nicholas. (1985-86). 'Wittgenstein's Criticism of Russell's Theory of Judgment.' Russell: The Journal of the Bertrand Russell Archives, 5(2): 132-145.

Hacker, P.M.S. (1972). Insight and Illusion: Wittgenstein on Philosophy and the Metaphysics of Experience. Oxford, UK: Clarendon Press.

Hanks, Peter W. (2007). 'How Wittgenstein Defeated Russell's Multiple Relation Theory of Judgment.' Synthese, 154(1): 121-46.

Kant, Immanuel. (1787/1990). Critique of Pure Reason. Trans. J.M.D. Meiklejon. Amherst, NY: Prometheus Books.

King, John and Desmond Lee. (1980). Wittgenstein's Lectures, Cambridge 1930-32. Oxford, UK: Blackwell Publishers.

Pears, David. (1987). The False Prison: A Study in the Development of Wittgenstein's Philosophy, Vol. 1. Oxford, UK: Clarendon Press.

Pereboom Derk. (2014). 'Kant's Transcendental Arguments', The Stanford Encyclopedia of Philosophy (Fall 2014 Edition), Edward N. Zalta (ed.,), $\mathrm{URL}=$ https://plato.stanford.edu/archives/fall2014/entries/kant-transcendental/

Pincock, Christopher. (2008). 'Russell's Last (and Best) Multiple Relation Theory of Judgment.' Mind, 117 (465): 107-140.

Rodych, Victor. 2011. 'Wittgenstein's Philosophy of Mathematics.' In The Stanford Encyclopedia of Philosophy, ed. Edward N. Zalta. URL $=<$ http:// plato.stanford.edu/archives/sum2011/entries/wittgenstein-mathematics/>.

Rogers, Brian and Kai F. Wehmeier. (2012). 'Tractarian First-Order Logic: Identity and the N-Operator.' The Review of Symbolic Logic, 5(4): 538-573.

Russell, Bertrand. (1905). 'On Denoting.' Mind, 14(56): 479-93. 
Russell, Bertrand. (1984). Theory of Knowledge: the 1913 Manuscript. Elizabeth Ramsden Eames and Kenneth Blackwell (eds.)). London, UK: George Allen \& Unwin.

Russell, Bertrand and Alfred North Whitehead. (1910-13/ 1997). Principia Mathematica to ${ }^{*} 56$. Cambridge, UK: Cambridge University Press.

Sommerville, Steven. (1979). Types, Categories, and Significance. Unpublished $\mathrm{PhD}$ Thesis, McMaster University.

Steinhart, Eric. (2009). More Precisely: The Math You Need to do Philosophy. Peterborough, ON, Canada: Broadview Press.

Stern, David G, Brian Rogers, and Gabriel Citron (eds.)). (2016) Wittgenstein Letures, Cambridge 1930-33: From the Notes of G.E. Moore. Cambridge, UK: Cambridge University Press.

Stevens, Graham. (2003). 'Re-examining Russell's Paralysis: Ramified TypeTheory and Wittgenstein's Objection to Russell's Theory of Judgment.' In Russell: The Journal of Bertrand Russell Studies, 23(1): 5-26.

Stevens, Graham. (2004). 'From Russell's Paradox to the Theory of Judgment: Wittgenstein and Russell on the Unity of the Proposition.' Theoria, 70: $28-60$.

Williams, Meredith. (1990). 'Wittgenstein, Kant and the "Metaphysics of Experience." Kant-Studien, 81(1): 69-88.

Wittgenstein, Ludwig. (1922). Tractatus Logico-Philosophicus. C.K. Odgen (trans.,). London, UK: Routledge \& Keegan Paul.

Wittgenstein, Ludwig. (1974). Tractatus Logico-Philosophicus. D.F. Pears and B.F. McGuiness (trans.,), with an introduction by Bertrand Russell. London and New York: Routledge.

Wittgenstein, Ludwig. (1978/ 1996). Remarks on the Foundations of Mathematics, Revised edition. G.E.M. Anscombe, Rush Rhees, and G.H. Von Wright, (eds.,). G.E.M. Anscombe (trans.)). Cambridge, Massachusetts: MIT Press.

Wittgenstein, Ludwig. (1995). Cambridge Letters: Correspondence with Russell, Keynes, Moore, Ramsey, and Sraffa,. Brian McGuiness and G.H. von Wright (eds.,). Oxford, UK: Basil Blackwell.

Wittgenstein, Ludwig. (2005). The Big Typescript: TS 213, German-English Scholar's Edition. C. Grant Luckhardt and Maximilian A.E. Aue (eds., and trans.). Malden, Massachusetts: Blackwell Publishing. 